\title{
Stimulated emission of near-infrared radiation by current injection into silicon (100) quantum well
}

\author{
S. Saito, ${ }^{1, a)}$ Y. Suwa,${ }^{2}$ H. Arimoto, ${ }^{3}$ N. Sakuma,${ }^{3}$ D. Hisamoto, ${ }^{1}$ H. Uchiyama, ${ }^{1}$ \\ J. Yamamoto, ${ }^{3}$ T. Sakamizu, $^{3}$ T. Mine, ${ }^{3}$ S. Kimura, ${ }^{3}$ T. Sugawara, ${ }^{3}$ and M. Aoki ${ }^{1}$ \\ ${ }^{1}$ Central Research Laboratory, Hitachi, Ltd., and SORST, Japan Science and Technology, Kokubunji, \\ Tokyo 185-8601, Japan \\ ${ }^{2}$ Advanced Research Laboratory, Hitachi, Ltd., Kokubunji, Tokyo 185-8601, Japan \\ ${ }^{3}$ Central Research Laboratory, Hitachi, Ltd., Kokubunji, Tokyo 185-8601, Japan
}

(Received 4 October 2009; accepted 12 November 2009; published online 14 December 2009)

\begin{abstract}
We describe the observation of stimulated emissions by current injections into a silicon quantum well. The device consists of a free standing membrane with a distributed feedback resonant cavity fabricated by state-of-the-art silicon processes. The emission spectra have multimode structures peaked in the near-infrared region above the submilliampere threshold currents at room temperatures. Consequently, electronics and photonics should be able to be converged on chips by using silicon quantum well laser diodes. (C) 2009 American Institute of Physics.
\end{abstract}

[doi:10.1063/1.3273367]

Transistors $^{1}$ and laser $^{2}$ diodes are two major inventions that support our ubiquitous electronics and telecommunication infrastructures. Integrating them on a chip by replacing global metal interconnections with optical interconnections is expected to achieve the next breakthrough in upgrading the chip because this will enable it to operate at even higher speed with lower power consumption. ${ }^{3}$ However, the fact that these two devices are made of different semiconductors-silicon and compound semiconductors, respectively-prevents their integration.

Among the various approaches for all-silicon based light sources, controlling quantum confinements ${ }^{4-12}$ in lowdimensional nanostructures is the most straightforward way to overcome the fundamental limitations of the indirect band gap structure in the bulk silicon. According to theoretical calculations, direct recombination without mediating phonons is possible in low-dimensional $\mathrm{Si}$ nanostructures, like quantum wells (QWs), ${ }^{13,14}$ nanowires, ${ }^{15,16}$ and nanodots, ${ }^{3}$ by using conduction band valley projections. ${ }^{14,17}$ A practical challenge concerning quantum confinements, however, has been a difficulty in injecting carriers into these $\mathrm{Si}$ nanostructures since the surface of $\mathrm{Si}$ is highly oxidized to form insulating $\mathrm{SiO}_{2}$. We previously showed lateral carrier injections ${ }^{18,19}$ into a $\mathrm{Si}(100) \mathrm{QW}$, the thickness of which is less than exciton Bohr radius $\sim 5 \mathrm{~nm}$, are compatible with quantum confinements. ${ }^{18}$

The next prerequisite for a Si QW laser diode (LD) is to induce stimulated emissions under population inversion conditions. According to our first principles calculations based on density functional theory, the optical gain is predicted to become positive in a $\mathrm{Si}(100) \mathrm{QW}$. However, it has not been experimentally verified whether a $\mathrm{Si} \mathrm{QW}$ exhibits intrinsic optical gain or not. The present work aims to observe the stimulated emissions in a $\mathrm{Si}(100) \mathrm{QW}$. We embedded the $\mathrm{Si}$ QW in a distributed feedback (DFB) resonant cavity fabricated by the $\mathrm{Si}$ complimentary-metal-oxide-semiconductor (CMOS) and nanoelectromechanical system (NEMS) technologies and observed stimulated emissions in the near-

${ }^{\text {a)} E l e c t r o n i c ~ m a i l: ~ s h i n i c h i . s a i t o . q t @ h i t a c h i . c o m . ~}$ infrared region by current injections at room temperatures.

The device structure of the Si QW DFB LD is shown in Fig. $1 .{ }^{20}$ The $3 \mathrm{~nm}$ thick Si $(100) \mathrm{QW}$ was formed by the local oxidation of silicon process ${ }^{9,11,12,18}$ on the $145 \mathrm{~nm}$ thick buried oxide (BOX) using silicon-on-insulator (SOI) substrates. The thick region of SOI was ion implanted to form $p^{+}$ and $n^{+}$diffusion regions and activated to make a lateral pin diode. The Si QW was kept undoped to reduce nonradiative recombinations at impurities. The resonant cavity is made of $\mathrm{Si}_{3} \mathrm{~N}_{4}$ grating mirrors within $\mathrm{SiO}_{2}$ clad layers on top of the $\mathrm{Si}$ QW. To make this grating, we just needed to deposit a $\mathrm{Si}_{3} \mathrm{~N}_{4}$ film followed by patterning by using electron beam lithogra-

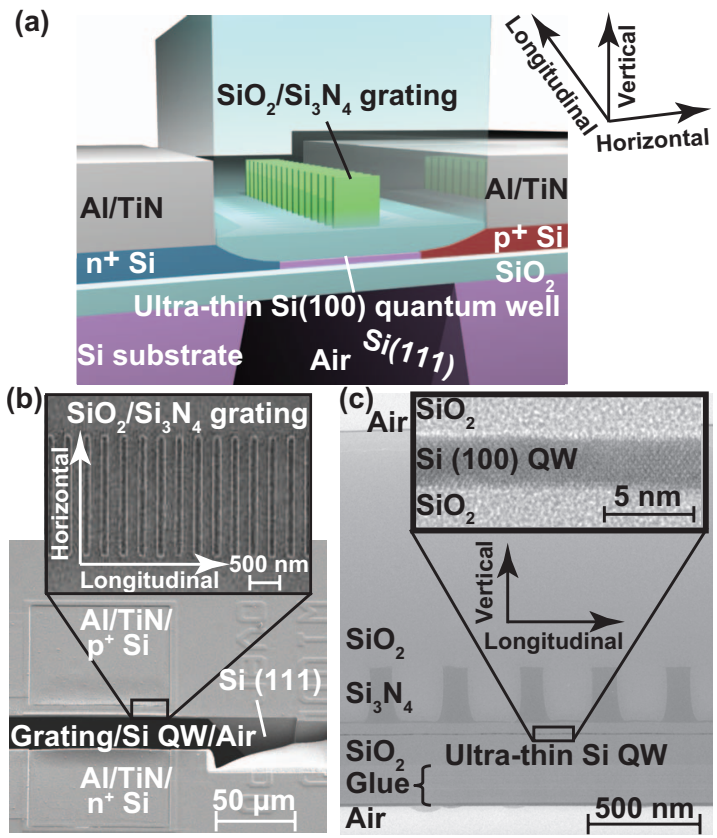

FIG. 1. (Color) Si quantum well (QW) laser diode (LD) with distributed feedback (DFB) resonant cavity. (a) Schematic device structures. Active channel width (length) is $100(10) \mu \mathrm{m}$ and cavity length (width) is 100(2) $\mu \mathrm{m}$. (b) Tilted scanning electron microscope (SEM) images after focused ion beam etching. Inset shows plan view of $\mathrm{SiO}_{2}$ and $\mathrm{Si}_{3} \mathrm{~N}_{4}$ grating. (c) Transmission electron microscope images after processing. Inset shows single crystal Si (100) QW. 


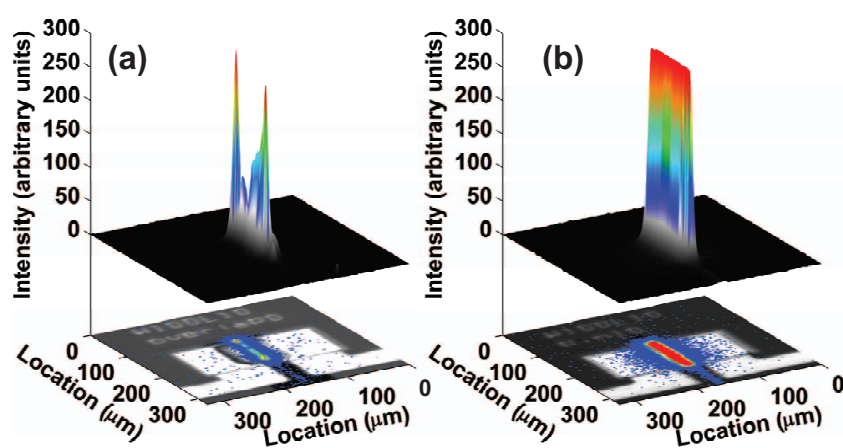

FIG. 2. (Color) Electroluminescence (EL) from Si QW. Images were obtained under constant current of $0.7 \mathrm{~mA}$ with integration time of $5 \mathrm{~s}$. (a) EL images from LD with resonant cavity. (b) EL images from reference device without cavity.

phy and subsequent dry etching, and finally embedding $\mathrm{SiO}_{2}$ by chemical vapor deposition. After these conventional $\mathrm{Si}$ processes, we made more than 300 pairs of $\mathrm{Si}_{3} \mathrm{~N}_{4}$ and $\mathrm{SiO}_{2}$ along with the longitudinal cavity. The strong optical feedback was expected due to the high reflective index difference between $\mathrm{Si}_{3} \mathrm{~N}_{4}$ and $\mathrm{SiO}_{2}$. The guided mode was effectively confined within a $\mathrm{Si}_{3} \mathrm{~N}_{4}$ core with the evanescent coupling $(\Gamma=0.63 \%)$ to the Si QW. After metallizing by Al/TiN stacks and $\mathrm{H}_{2}$ annealing to passivate the $\mathrm{Si} / \mathrm{SiO}_{2}$ interface traps, the $\mathrm{Si}_{3} \mathrm{~N}_{4}$ film deposited on the backside of the $\mathrm{Si}$ substrate was patterned by lithography and dry etching with the alignment to the front side. By using the $\mathrm{Si}_{3} \mathrm{~N}_{4}$ patterns as a hard mask, the slit aperture of the supporting $\mathrm{Si}$ substrate was locally made by anisotropic wet etching to avoid the tunneling leakage of photons into the Si substrate, similar to the photonic crystal microcavity laser ${ }^{21}$ utilizing air-slab structures and silicon membrane separating macromolecule. ${ }^{22}$ The huge difference in etching rates between $\mathrm{Si}$ and $\mathrm{SiO}_{2}$ was required to remove the $725 \mu \mathrm{m}$ thick $\mathrm{Si}$ substrate below the BOX layer. The suspended membrane, which was just $1.3 \mu \mathrm{m}$ thick, contained $\sim 3 \mathrm{~nm}$ thick Si QW, the single crystal structure of which was preserved after processing [Fig. 1(c)]. We also fabricated a device without the resonant cavity for comparison.

All measurements were performed at room temperatures. EL images with the spatial resolution of $2.6 \mu \mathrm{m}$ and spectra were taken by a charge-coupled-device (CCD) cooled down to $-75{ }^{\circ} \mathrm{C}$. Both images and spectra were taken at specific exposure time under continuous wave or pulsed operations.
We examined the EL from the top since we could not dice the wafer due to its fragile structure.

Most of the EL was observed from the edge of the resonant cavity, and the emission from the center of the cavity was suppressed [Fig. 2(a), Ref. 20]. This confirms that the $\mathrm{Si}_{3} \mathrm{~N}_{4}$ grating works as the core of the cavity to confine photons. By contrast, in the device without the cavity, the EL was observed from the entire Si QW [Fig. 2(b)], and the spontaneous emissions spread in all directions. ${ }^{18}$

Next, we examined the EL spectra from the device [Fig. 3(a)]. The spectra were taken by collecting EL emissions using objective lenses and focusing them on a bundled optical fiber. To remove the impact of cosmic rays in the CCD detector, each measurement was repeated at least five times, and the data without the spikes were used for analysis.

We applied forward voltage pulses with a width of 100 ns and a period of $1 \mu$ s to the device. Under pulsed operations, we clearly observed the resonant modes peaked with a width of $\sim 1 \mathrm{~nm}$ at $996,994,889$, and $875 \mathrm{~nm}$, the intensities of which increased as voltages increased [Fig. 3(a)]. The peaks were from the resonant cavity modes, since there was no peak structure for the reference device without the resonant cavity. We designed so that the center of the photonic band gap was located at $950 \mathrm{~nm}$, and therefore, the resonant peaks were from emissions at the edges of the stop bands of the resonant cavity. The multimode spectra were expected since the cavity contained many modes in both vertical and horizontal directions.

The spectra have maxima at the emission wavelength $\lambda$ of $\sim 1000 \mathrm{~nm}$ corresponding to the band gap $E_{\mathrm{g}}$ of $1.24 \mathrm{eV}$, which was widened from that of the bulk $\left(E_{\mathrm{g}}=1.1 \mathrm{eV}\right)$ (Refs. 19 and 23) due to the quantum confinement. ${ }^{4-10,14,18}$ The blueshift was smaller than that of Si nanocrystals $\left(\lambda=850 \mathrm{~nm}, E_{\mathrm{g}}=1.46 \mathrm{eV}\right),{ }^{10}$ as expected from the two-dimensional nature of the Si QW.

The resonant peaks at 994 and $996 \mathrm{~nm}$ in Fig. 3(a) were split by the Gaussian fittings from the broad background, and the integrated EL intensity $L$ of each resonant modes are shown in Fig. 3(b). We found the finite threshold currents of $I_{\text {th } 1}=0.31 \mathrm{~mA}$ and $I_{\text {th2 }}=0.44 \mathrm{~mA}$ for the peaks at 994 and $996 \mathrm{~nm}$, respectively. The observed submilliampere order threshold currents were not surprising, since the current density was extremely high $\sim 0.31 \mathrm{~mA} / 100 \mu \mathrm{m} / 3 \mathrm{~nm}$ $\sim 100 \mathrm{kA} / \mathrm{cm}^{2}$, comparable to that of the laser operation in GaAs without double heterostructures. ${ }^{24}$ Such a high current
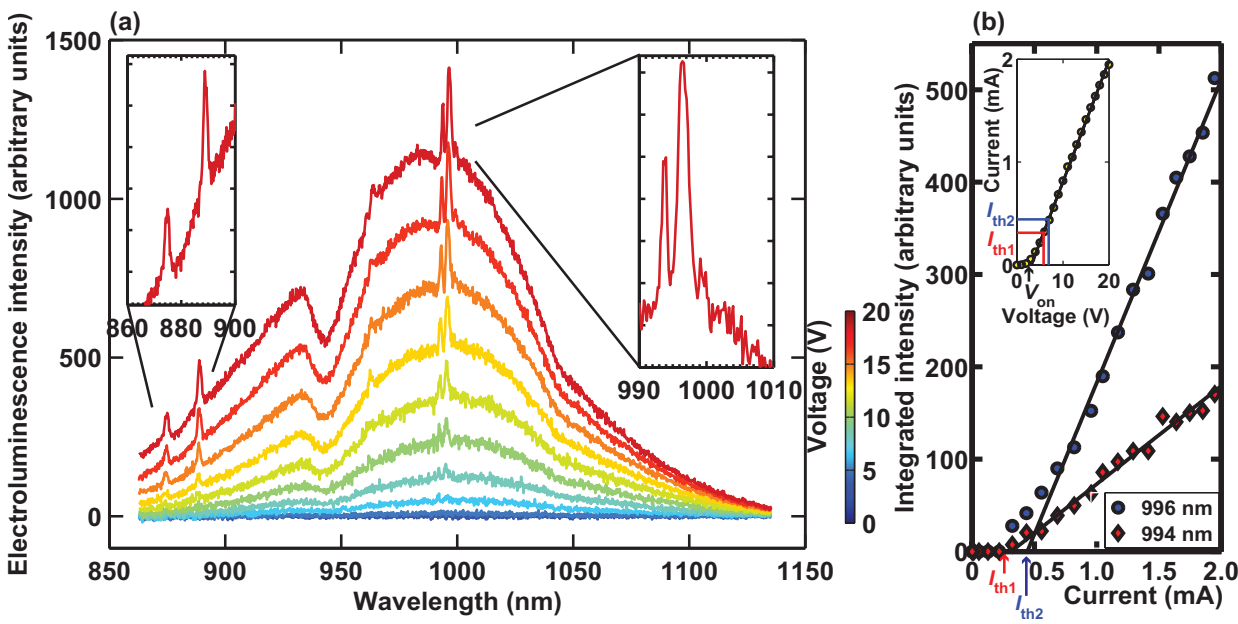

FIG. 3. (Color) Stimulated emission from Si QW DFB LD. (a) EL spectra. Data are shown with applied voltage of 0 to $20 \mathrm{~V}$ with $2 \mathrm{~V}$ steps. Integration time was $60 \mathrm{~s}$. Dips around 940 $\mathrm{nm}$ originate from optical loss due to fiber, not device. Insets show enlarged spectra around resonant peaks. (b) Threshold characteristics. Inset shows current-voltage characteristics. Finite threshold currents were observed after onset of diode $V_{\mathrm{on}}$. 
density is applicable to $\mathrm{Si}$ technologies due to the solid solubility densities of impurities $\left(\sim 10^{20} \mathrm{~cm}^{-3}\right)$ higher than those of compound semiconductors. In the reference device without the cavity, $L$ linearly increased with no $I_{\text {th }}$, indicating spontaneous emissions. Therefore, the finite $I_{\text {th }}$ was the result of strong optical feedback by the $\mathrm{SiO}_{2} / \mathrm{Si}_{3} \mathrm{~N}_{4}$ grating and the optical gain from the Si QW. We have estimated that the minimum effective gain $g_{\text {eff }}$ required for the lasing is $0.26 \mathrm{~cm}^{-1}$, which corresponds to the material gain $g$ $=g_{\text {eff }} / \Gamma$ of $42 \mathrm{~cm}^{-1}$. Such a small threshold gain came from the large difference in the dielectric constant between $\mathrm{SiO}_{2}$ and $\mathrm{Si}_{3} \mathrm{~N}_{4}$. The magnitude of $g$ is comparable to theoretical predictions. $^{14}$

These results show that stimulated emissions from the $\mathrm{Si}$ QW by current injections at room temperatures are indeed possible within experimental conditions accessible to the current $\mathrm{Si}$ technologies. The maximum currents in the present device were limited due to self-heating, which should be avoided by using SOI substrates with a thicker BOX layer rather than the slit aperture structure. After the device performance improves, the Si QW LDs should be highly integrated with CMOS transistors for future on-chip optical interconnections.

We thank K. Takeda, T. Takahama, T. Takahashi, I. Uchida, S. Morita, T. Morimoto, M. Kawano, T. Yamamoto, H. Ichizoe, K. Endo, N. Oshima, N. Higuchi, H. Hamamura, K. Fujisaki, and K. Hozawa for help in device fabrication, and we also thank M. Nakamura, T. Onai, N. Osakabe, K. Torii, R. Tsuchiya, Y. Matsui, H. Yoshimoto, I. Yanagi, and T. Arai for enlightening discussions.

${ }^{1}$ J. Bardeen and W. H. Brattain, Phys. Rev. 74, 230 (1948).

${ }^{2}$ A. L. Schawlow and C. H. Townes, Phys. Rev. 112, 1940 (1958).

${ }^{3}$ S. Ossicini, L. Pavesi, and F. Priolo, Light Emitting Silicon for Micropho- tonics (Springer, Berlin, 2003).

${ }^{4}$ L. T. Canham, Appl. Phys. Lett. 57, 1046 (1990).

${ }^{5}$ N. Koshida and H. Koyama, Appl. Phys. Lett. 60, 347 (1992).

${ }^{6}$ Y. Takahashi, T. Furuta, Y. Ono, T. Ishiyama, and M. Tabe, Jpn. J. Appl. Phys., Part 1 34, 950 (1995).

${ }^{7}$ Z. H. Lu, D. J. Lockwood, and J. M. Baribeau, Nature (London) 378, 258 (1995).

${ }^{8}$ D. J. Lockwood, Z. H. Lu, and J. M. Baribeau, Phys. Rev. Lett. 76, 539 (1996).

${ }^{9}$ N. Pauc, V. Calvo, J. Eymery, F. Fournel, and N. Magnea, Phys. Rev. Lett. 92, 236802 (2004).

${ }^{10}$ L. Pavesi, L. D. Negro, C. Mazzoleni, G. Franzò, and F. Priolo, Nature (London) 408, 440 (2000)

${ }^{11}$ Z. H. Lu and D. Grozea, Appl. Phys. Lett. 80, 255 (2002).

${ }^{12}$ D. J. Lockwood, M. W. C. Dharma-wardana, Z. H. Lu, D. H. Grozea, P. Carrier, and L. J. Lewis, Quantum Confined Semiconductor Nanostructures, MRS Symposia Proceedings No. 737 (Materials Research Society, Pittsburgh, 2003), p. F1.1.1.

${ }^{13}$ M. Nishida, Phys. Rev. B 58, 7103 (1998).

${ }^{14}$ Y. Suwa and S. Saito, Phys. Rev. B 79, 233308 (2009).

${ }^{15}$ T. Ohno, K. Shiraishi, and T. Ogawa, Phys. Rev. Lett. 69, 2400 (1992).

${ }^{16}$ X. Zhao, C. M. Wei, L. Yang, and M. Y. Chou, Phys. Rev. Lett. 92 236805 (2004).

${ }^{17}$ L. J. Sham, S. J. Allen, A. Kamgar, and D. C. Tsui, Phys. Rev. Lett. 40 472 (1978).

${ }^{18}$ S. Saito, D. Hisamoto, H. Shimizu, H. Hamamura, R. Tsuchiya, Y. Matsui, T. Mine, T. Arai, N. Sugii, K. Torii, S. Kimura, and T. Onai, Jpn. J. Appl. Phys., Part 2 45, L679 (2006); Appl. Phys. Lett. 89, 163504 (2006).

${ }^{19}$ T. Hoang, P. LeMinh, J. Holleman, and J. Schmitz, IEEE Electron Device Lett. 27, 105 (2006)

${ }^{20}$ See EPAPS supplementary material at http://dx.doi.org/10.1063/ 1.3273367 for the video images.

${ }^{21}$ O. Painter, R. K. Lee, A. Scherer, A. Yariv, J. D. O’Brien, P. D. Dapkus, and I. Kim, Science 284, 1819 (1999).

${ }^{22}$ C. C. Striemer, T. R. Gaborski, J. L. McGrath, and P. M. Fauchet, Nature (London) 445, 749 (2007).

${ }^{23}$ M. J. Chen, J. L. Yen, J. Y. Li, J. F. Chang, S. C. Tsai, and C. S. Tsai, Appl. Phys. Lett. 84, 2163 (2004).

${ }^{24}$ R. N. Hall, G. E. F. J. D. Kingsley, T. J. Soltys, and R. O. Carlson, Phys Rev. Lett. 9, 366 (1962). 